\title{
Cardiac metabolism in a new rat model of type 2 diabetes using high-fat diet with low dose streptozotocin
}

\author{
Latt S Mansor ${ }^{1}$, Eileen R Gonzalez ${ }^{1}$, Mark A Cole ${ }^{1,2}$, Damian J Tyler ${ }^{1}$, Jessica H Beeson ${ }^{1}$, Kieran Clarke ${ }^{1}$,
} Carolyn A Carr ${ }^{1}$ and Lisa C Heather ${ }^{1 *}$

\begin{abstract}
Background: To study the pathogenesis of diabetic cardiomyopathy, reliable animal models of type 2 diabetes are required. Physiologically relevant rodent models are needed, which not only replicate the human pathology but also mimic the disease process. Here we characterised cardiac metabolic abnormalities, and investigated the optimal experimental approach for inducing disease, in a new model of type 2 diabetes.

Methods and results: Male Wistar rats were fed a high-fat diet for three weeks, with a single intraperitoneal injection of low dose streptozotocin (STZ) after fourteen days at 15, 20, 25 or $30 \mathrm{mg} / \mathrm{kg}$ body weight. Compared with chow-fed or high-fat diet fed control rats, a high-fat diet in combination with doses of $15-25 \mathrm{mg} / \mathrm{kg}$ STZ did not change insulin concentrations and rats maintained body weight. In contrast, $30 \mathrm{mg} / \mathrm{kg}$ STZ induced hypoinsulinaemia, hyperketonaemia and weight loss. There was a dose-dependent increase in blood glucose and plasma lipids with increasing concentrations of STZ. Cardiac and hepatic triglycerides were increased by all doses of STZ, in contrast, cardiac glycogen concentrations increased in a dose-dependent manner with increasing STZ concentrations. Cardiac glucose transporter 4 protein levels were decreased, whereas fatty acid metabolismregulated proteins, including uncoupling protein 3 and pyruvate dehydrogenase (PDH) kinase 4, were increased with increasing doses of STZ. Cardiac PDH activity displayed a dose-dependent relationship between enzyme activity and STZ concentration. Cardiac insulin-stimulated glycolytic rates were decreased by $17 \%$ in $15 \mathrm{mg} / \mathrm{kg}$ STZ high-fat fed diabetic rats compared with control rats, with no effect on cardiac contractile function.
\end{abstract}

Conclusions: High-fat feeding in combination with a low dose of STZ induced cardiac metabolic changes that mirror the decrease in glucose metabolism and increase in fat metabolism in diabetic patients. While low doses of 15-25 mg/kg STZ induced a type 2 diabetic phenotype, higher doses more closely recapitulated type 1 diabetes, demonstrating that the severity of diabetes can be modified according to the requirements of the study.

\section{Introduction}

The incidence of type 2 diabetes continues to increase, despite the best current therapies and educational programs available. Cardiovascular disease is the leading cause of mortality in type 2 diabetic patients in the United Kingdom [1]. Metabolic changes in the heart have been implicated in the increased incidence of myocardial infarction [2], with diabetic patients having decreased cardiac glucose metabolism and increased

\footnotetext{
* Correspondence: Lisa.heather@dpag.ox.ac.uk

'Department of Physiology, Anatomy and Genetics, University of Oxford, Parks Road, OX13PT, Oxford, UK

Full list of author information is available at the end of the article
}

cardiac fatty acid metabolism [3-6]. Therefore, a greater understanding of how type 2 diabetes affects the heart, the role of abnormal cardiac metabolism and how novel interventions could circumvent this are needed.

Animal models of type 2 diabetes are currently the first line for investigating disease mechanisms and pharmacological therapies. For relevance to humans, animal models must replicate the phenotype seen in patients as closely as possible, but it is also desirable that they mimic the developmental process of the disease. From a practical perspective, models that are easy to generate, cheap and develop in a timely manner will be favoured over expensive and time-consuming models. 
No animal models are perfect, and current rodent models of type 2 diabetes have been associated with a number of drawbacks (comprehensively reviewed by Bugger and Abel [7]). For example, the $d b / d b$ mouse, $o b / o b$ mouse and Zucker fatty rat have been extensively studied in the literature [8-11], and are generated by genetic abnormalities in the leptin signalling pathway, whereas, in patients, type 2 diabetes usually results as a consequence of multiple gene polymorphisms in combination with environmental factors. Similarly, the GotoKakizaki GK rat is insulin resistant but remains lean [12,13], making comparisons to the human condition and its association with obesity difficult. Another drawback of spontaneously diabetic and transgenic animals is the expensive cost of purchase [14]. In relation to cardiac research, one of the limitations of current rat models is the extended periods taken to develop cardiac phenotypes, despite the presence of abnormal circulating metabolites from an early age. For example, Zucker diabetic rats only show cardiac metabolic dysfunction after 12 weeks of age [15], and Zucker fatty rats only after 12 months [16]. Similarly, high-fat diet alone isn't effective at modifying cardiac and systemic metabolism unless fed over an extended period [17].

A relatively new rat model was proposed first by Reed et al. [18], with modifications by Srinivasan et al. [19], which aimed to induce type 2 diabetes by using high-fat feeding to induce peripheral insulin resistance, followed by a low dose of the pancreatic $\beta$-cell toxin, streptozotocin (STZ). STZ is traditionally used at high doses to induce type 1 diabetes, as it results in impaired insulin secretion from the $\beta$-cell $[20,21]$. Reed et al. proposed that if a low dose of STZ was used after high-fat feeding, the function of the $\beta$-cell mass would be modestly impaired without completely compromising insulin secretion, resulting in a moderate impairment in glucose tolerance $[18,19]$. This would mimic the human disease process resulting in a metabolic phenotype similar to that in late stage type 2 diabetic patients. This model has become increasingly popular in recent years, both for investigating the mechanisms involved in type 2 diabetes and for testing potential therapies [22-26]. However, the degree of diabetes induced, the amount of STZ used, background strain and starting body weight vary considerably between these studies. As examples, Reed et al. administered $50 \mathrm{mg} / \mathrm{kg}$ STZ via an intravenous route following anaesthesia, Srinivasan et al. used $35 \mathrm{mg} / \mathrm{kg} \mathrm{STZ}$ administered intraperitoneally but using relatively juvenile rats, whereas Zhang et al. fed rats on a high-fat diet for 2 months prior to STZ $[18,19,27]$. Therefore, a better understanding of the cardiac phenotype of this model, the metabolic changes associated with this method of inducing diabetes and determining the optimal protocol would be desirable prior to use in large scale studies.
Therefore, we set out to determine whether this high-fat feeding/low dose STZ model of type 2 diabetes modified cardiac metabolism in a similar manner to the human disease. In addition, we aimed to determine the optimal experimental approach to induce the disease by testing the cardiac effects of a variety of STZ doses in mature adult Wistar rats. Rats were fed a high-fat diet for three weeks, with a single intraperitoneal injection of STZ of either 15, 20, 25 or $30 \mathrm{mg} / \mathrm{kg}$ body weight after two weeks. Our results showed that inducing type 2 diabetes, using a combination of highfat feeding with a low dose of STZ, mimics the human condition. We also demonstrate that while low doses of STZ induced type 2 diabetes and cardiac metabolic changes, a dose of $30 \mathrm{mg} / \mathrm{kg}$ induced overt and severe systemic alterations that more closely resembled type 1 diabetes.

\section{Methods}

\section{Rat model of type 2 diabetes}

Male Wistar rats $(\mathrm{n}=55,260 \pm 7 \mathrm{~g})$ were obtained from a commercial breeder (Harlan, UK). All procedures were in accordance with Home Office (UK) guidelines under The Animals (Scientific Procedures) Act, 1986 and with institutional guidelines. Control rats were fed for three weeks on a standard chow diet (Harlan Laboratories), with an Atwater Fuel Energy of $3.0 \mathrm{kcal} / \mathrm{g}$, comprising $66 \%$ calories from carbohydrate, $22 \%$ from protein and $12 \%$ from fat (Additional file 1: Table S1). To induce diabetes, rats were fed a high-fat diet (Special Diet Services) for three weeks, with an Atwater Fuel Energy of $5.3 \mathrm{kcal} / \mathrm{g}$, comprising $60 \%$ calories from fat, $35 \%$ from protein and $5 \%$ from carbohydrate, according to a modification of the protocols of Reed et al. and Srinivasan et al. [18,19]. On day 13 , rats were fasted overnight and given a single intraperitoneal injection of streptozotocin (STZ in citrate buffer, $\mathrm{pH} 4$ ) the following morning, and the high-fat diet feeding was continued for a further week (or chow diet for controls). Different doses of STZ (0, 15, 20, 25 and $30 \mathrm{mg} / \mathrm{kg}$ bodyweight $w / w)$ in combination with high-fat diet, were investigated to determine the optimal dose to induce a type 2 diabetic phenotype with modified cardiac metabolism. We started our study with a dose of $30 \mathrm{mg} / \mathrm{kg}$, to closely replicate that used by others [19], then included additional groups on lower doses of STZ until hyperglycaemia was no longer induced, mortality was not observed with any dose of STZ. After three weeks on their designated diet, rats in the fed state were terminally anaesthetised with sodium pentobarbital, hearts and livers were rapidly excised, freeze clamped and stored at $-80^{\circ} \mathrm{C}$ for subsequent analysis. Following excision of the heart, blood was collected from the chest cavity, plasma separated and analysed for metabolites using a Pentra analyser (ABX, UK) and an insulin ELISA (Mercodia, Sweden). Both left and right epididymal fat pads were excised, trimmed and weighed, for assessment of adiposity. 


\section{Tissue analysis}

Cardiac and hepatic glycogen content were determined by the breakdown of glycogen to glucose units, using amyloglucosidase. Triglyceride content was measured in cardiac and hepatic tissue, following Folch extraction, using a kit from Randox, UK. The active fraction of pyruvate dehydrogenase was assayed in cardiac homogenates according to the protocol of Seymour et al. [28]. Medium chain acyl-coenzyme A dehydrogenase activity in cardiac homogenates was measured by following the decrease in ferricinium ion absorbance, as described by Lehman et al. [29]. Citrate synthase activity was measured in cardiac homogenates according to the method of Srere [30].

\section{Western blotting}

Cardiac lysates were prepared from frozen tissue and equal concentrations of protein were loaded and separated on 12.5\% SDS-PAGE gels, and transferred onto immobilon-p membranes (Millipore, UK) [31]. FAT/ CD36 was detected with an antibody kindly donated by Dr Narendra Tandon (Otsuka Maryland Medicinal Laboratories, USA) [32]. Prof. Geoff Holman (University of Bath, UK) kindly donated the GLUT4 antibody [33,34]. PDK4 was detected using an antibody kindly donated by Prof. Mary Sugden (Queen Mary's, University of London, UK) [35]. Antibodies against GLUT1 and UCP3 were purchased from Abcam, UK, and against monocarboxylate transporter (MCT) 1 from Santa Cruz. Even protein loading and transfer were confirmed by Ponceau staining.

\section{Isolated heart perfusion}

A second group of rats were treated with the lowest dose of STZ $(15 \mathrm{mg} / \mathrm{kg})$ in combination with high-fat diet, to investigate the effect on cardiac glycolytic flux in the isolated perfused heart. Hearts were isolated into ice-cold Krebs-Henseleit (KH) buffer, cannulated via the aorta and perfused in Langendorff mode at a constant perfusion pressure of $100 \mathrm{mmHg}$ at $37^{\circ} \mathrm{C}$ [31]. Hearts were perfused with $200 \mathrm{ml}$ recirculating $\mathrm{KH}$ buffer (118 mM NaCl, $4.7 \mathrm{mM} \mathrm{KCl,} 1.2 \mathrm{mM} \mathrm{MgSO}, 1.3 \mathrm{mM}$ $\mathrm{CaCl}_{2}, 0.5 \mathrm{mM}$ EDTA, $25 \mathrm{mM} \mathrm{NaHCO}_{3}, 1.2 \mathrm{mM}$ $\mathrm{KH}_{2} \mathrm{PO}_{4}, \mathrm{pH} 7.4$ ) containing $11 \mathrm{mM}$ glucose and $3 \mathrm{U} / \mathrm{L}$ insulin, gassed with $95 \% \mathrm{O}_{2}$ and $5 \% \mathrm{CO}_{2}$.

To measure functional changes during the perfusion protocol, a fluid filled, PVC balloon was inserted into the left ventricle, inflated to achieve an end-diastolic pressure of $4 \mathrm{mmHg}$, and attached via a polyethylene tube to a bridge amplifier and PowerLab data acquisition system (ADInstruments, Oxfordshire, UK). Left ventricular developed pressure was determined as systolic pressure minus end-diastolic pressure. Rate pressure product was calculated as the product of developed pressure and heart rate. To measure glycolytic rates, the $\mathrm{KH}$ buffer was supplemented with $0.2 \mu \mathrm{Ci} \cdot \mathrm{ml}^{-1}\left[5^{-3} \mathrm{H}\right]$ glucose and timed aliquots of perfusate were collected during the perfusion protocol. Glycolytic rates were determined from the conversion of ${ }^{3} \mathrm{H}$-glucose to ${ }^{3} \mathrm{H}_{2} \mathrm{O}$ in the aliquots.

\section{Statistics}

Results are presented as means \pm SEM, and were considered significant at $\mathrm{p}<0.05$ (SPSS Statistics 18). Differences between all six groups (control, 0, 15, 20, 25 and $30 \mathrm{mg} / \mathrm{kg}$ STZ) were investigated using a one-way ANOVA with Tukey post-hoc correction for multiple comparisons. To investigate the STZ dose-dependent effects, a two tailed regression analysis was performed between the five doses of STZ.

\section{Results}

\section{Physical parameters}

Control rats gained $69 \pm 3 \mathrm{~g}$ in body weight over the three week protocol, averaging $23 \pm 4$ g per week (Table 1 and Additional file 2: Figure S1). Following the injection of STZ at day 14, the lower doses of STZ $(0,15,20$ and $25 \mathrm{mg} / \mathrm{kg}$ ) did not alter total body weight gain or body weight gain in the final week compared with the control

Table 1 Physical parameters from control and diabetic rats, induced using high-fat feeding in combination with low dose STZ

Diabetes mode

(High-fat feeding with low dose STZ)

\begin{tabular}{|c|c|c|c|c|c|c|}
\hline & Control & $0 \mathrm{mg} / \mathrm{kg}$ & $15 \mathrm{mg} / \mathrm{kg}$ & $20 \mathrm{mg} / \mathrm{kg}$ & $25 \mathrm{mg} / \mathrm{kg}$ & $30 \mathrm{mg} / \mathrm{kg}$ \\
\hline Total body weight gain $(\mathrm{g})$ & $69 \pm 3$ & $82 \pm 7$ & $88 \pm 15$ & $93 \pm 5$ & $77 \pm 9$ & $50 \pm 9 \#$ \\
\hline Body weight change during two weeks of diet modification (g) & $46 \pm 1$ & $49 \pm 7$ & $56 \pm 12$ & $60 \pm 2$ & $55 \pm 8$ & $55 \pm 7$ \\
\hline Body weight change in final week following STZ or control (g) & $23 \pm 4$ & $33 \pm 5$ & $32 \pm 2$ & $33 \pm 3$ & $22 \pm 4$ & $-5 \pm 4 * \dagger$ \\
\hline Epidydimal fat pad weight (g) & $4.8 \pm 0.4$ & $7.0 \pm 0.7$ & $5.7 \pm 0.4$ & $7.6 \pm 0.7$ & $9.8 \pm 0.6 * \#$ & $8.3 \pm 0.7 *$ \\
\hline Epidydimal fat pad to body weight ratio (\%) & $1.5 \pm 0.1$ & $2.0 \pm 0.2$ & $1.8 \pm 0.1$ & $2.4 \pm 0.2 *$ & $2.5 \pm 0.1 *$ & $2.3 \pm 0.2 *$ \\
\hline Heart weight $(g)$ & $1.2 \pm 0.1$ & $1.2 \pm 0.1$ & $1.1 \pm 0.1$ & $1.1 \pm 0.1$ & $1.0 \pm 0.1$ & $1.1 \pm 0.1$ \\
\hline Heart to body weight ratio $\left(\times 10^{3}\right)$ & $3.6 \pm 0.2$ & $3.5 \pm 0.1$ & $3.4 \pm 0.2$ & $3.4 \pm 0.2$ & $3.2 \pm 0.2$ & $3.1 \pm 0.1$ \\
\hline
\end{tabular}

${ }^{*} p<0.05$ vs. control, $+p<0.05$ vs. all other doses of $S T Z, \# p<0.05$ vs. $15 \mathrm{mg} / \mathrm{kg} \mathrm{STZ.} \mathrm{n}=11$ for control groups, $\mathrm{n}=4$ for diabetic groups. 
Table 2 Plasma metabolites from control and diabetic rats in the fed state, induced using high-fat feeding in combination with low dose STZ

Diabetes model

(High-fat feeding with low dose STZ)

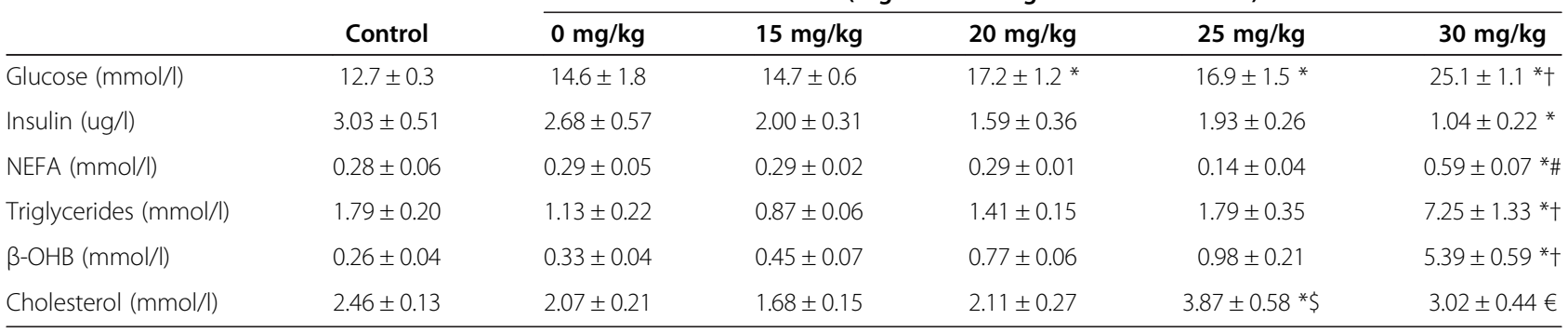

${ }^{*} \mathrm{p}<0.05$ vs. control, $+\mathrm{p}<0.05$ vs. all other doses of $\mathrm{STZ}, \# \mathrm{p}<0.05 \mathrm{vs} .15$ and $25 \mathrm{mg} / \mathrm{kg}, \$ \mathrm{p}<0.05$ vs. 0,15 and $20 \mathrm{mg} / \mathrm{kg}, € \mathrm{p}<0.05 \mathrm{vs}$. $15 \mathrm{mg} / \mathrm{kg}$. NEFA nonesterified fatty acids, $\beta$-OHB $\beta$-hydroxybutyrate, control $n=11$, for diabetic groups $n=4$.

group. In contrast, the $30 \mathrm{mg} / \mathrm{kg}$ STZ dose induced weight loss in the final week despite the continuation of the high-fat diet, compared with the control group and other lower doses of STZ. There was a significant correlation between body weight gain in the final week and STZ doses $\left(\mathrm{r}^{2}=0.33, \mathrm{p}<0.05\right)$. Epididymal fat pad weight, an indicator of total body adiposity, and fat pad to body weight ratio were significantly increased with higher doses of STZ compared with controls. Heart weight and heart weight to body weight ratio were not significantly different between any groups, demonstrating no significant cardiac hypertrophy.

\section{Plasma metabolites in the fed state}

Blood glucose concentrations were not increased by high-fat diet alone or in combination with $15 \mathrm{mg} / \mathrm{kg}$ STZ, compared with control chow fed rats (Table 2). In contrast, blood glucose levels were increased by 20, 25 and $30 \mathrm{mg} / \mathrm{kg} \mathrm{STZ}$ in combination with a high-fat diet, with the $30 \mathrm{mg} / \mathrm{kg} \mathrm{STZ} \mathrm{dose} \mathrm{increasing} \mathrm{blood} \mathrm{glucose}$ significantly higher than all other groups. Plasma insulin concentrations were not significantly different to control animals at lower doses of STZ, but were significantly decreased by $30 \mathrm{mg} / \mathrm{kg} \mathrm{STZ}$. Non-esterified fatty acids (NEFA), triglyceride, and $\beta$-hydroxybutyrate $(\beta-\mathrm{OHB})$ concentrations were increased only with the highest dose of STZ (30 mg/kg), compared with controls and the other doses of STZ investigated. Cholesterol concentrations were elevated by administration of $25 \mathrm{mg} / \mathrm{kg} \mathrm{STZ}$ in combination with high-fat feeding compared with controls and lower doses of STZ. Regression analysis demonstrated significant positive relationships between STZ dose and plasma glucose $\left(\mathrm{r}^{2}=0.37\right)$, triglycerides $\left(\mathrm{r}^{2}=\right.$ $0.30), \beta-O H B\left(r^{2}=0.41\right)$ and cholesterol $\left(r^{2}=0.20\right)$, and significant negative relationships between STZ dose and plasma insulin $\left(\mathrm{r}^{2}=0.25\right)(\mathrm{p}<0.05$ for all). Thus, while lower doses of $20-25 \mathrm{mg} / \mathrm{kg} \mathrm{STZ}$ were sufficient to elevate blood glucose levels without impairing insulin secretion, the higher dose of STZ caused severe diabetes, as shown by increased glucose, $\beta-\mathrm{OHB}$, triglycerides and decreased insulin concentrations.

\section{Hepatic intracellular substrate stores}

Hepatic triglyceride and glycogen stores were measured as an indicator of changes in liver metabolism. Three weeks of high-fat diet alone did not change hepatic triglyceride or glycogen concentrations compared with controls (Figure 1). Combining high-fat diet with all doses of STZ tested increased hepatic triglyceride concentrations, compared with control rat livers. In contrast, hepatic glycogen concentrations were decreased following

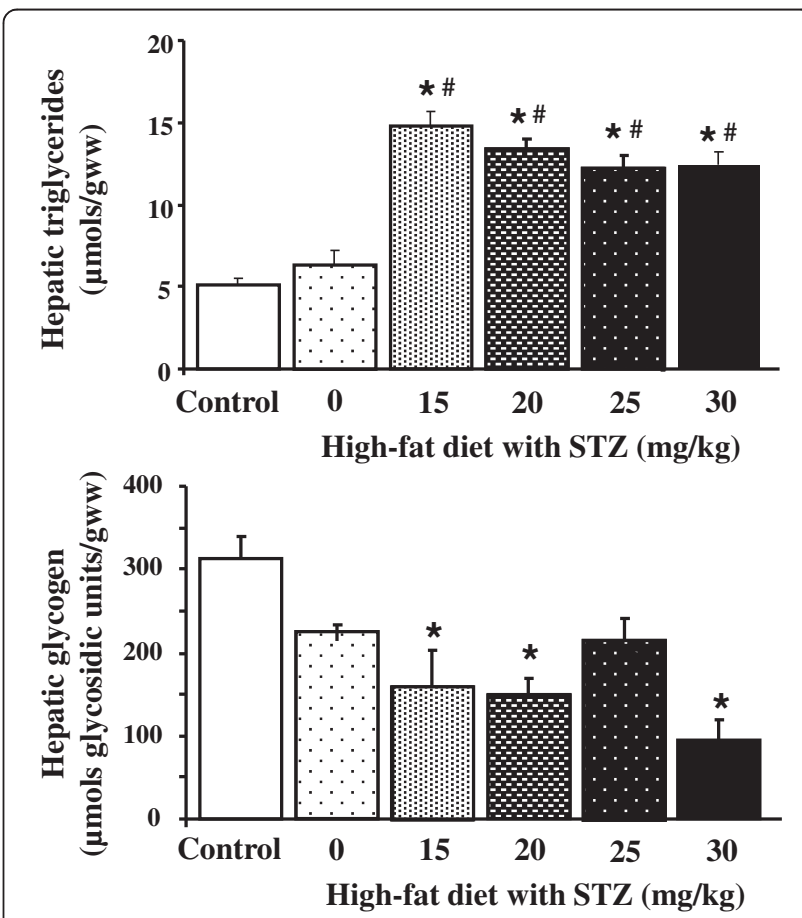

Figure 1 Hepatic triglyceride and glycogen concentrations in control and diabetic rats following high-fat feeding in combination with low dose STZ. * $p<0.05$ vs. control, \# $p<0.05$ vs. high-fat only, $\mathrm{n}=10$ for control group, $\mathrm{n}=4$ for diabetic groups. 
induction of diabetes using high-fat feeding in combination with STZ at doses of 15, 20 and $30 \mathrm{mg} / \mathrm{kg} \mathrm{STZ.} \mathrm{Both}$ measurements correlated with STZ dose (triglycerides $\mathrm{r}^{2}$ $=0.39$, glycogen $\left.\mathrm{r}^{2}=0.23, \mathrm{p}<0.05\right)$.

\section{Cardiac intracellular substrate stores}

One of the main aims of this study was to characterise the cardiac metabolic phenotype of this new model of type 2 diabetes. Cardiac triglyceride concentrations were increased by all doses of STZ tested, compared with control rats, but not by high-fat diet alone, displaying a significant positive correlation with STZ dose (Figure 2). Cardiac glycogen concentrations were decreased by high-fat diet and lower doses of STZ (15 and $20 \mathrm{mg} / \mathrm{kg}$ ), but showed a dose-dependent increase with STZ concentration. The highest dose of STZ tested $(30 \mathrm{mg} / \mathrm{kg}$ ) did not change cardiac glycogen concentrations compared with controls, and was significantly higher than lower doses of STZ (15 and $20 \mathrm{mg} / \mathrm{kg}$ ).

\section{Cardiac enzyme assays}

Cardiac pyruvate dehydrogenase (PDH) activity, a heavily regulated enzyme of mitochondrial glucose metabolism, was significantly decreased in diabetic hearts at a dose of $30 \mathrm{mg} / \mathrm{kg} \mathrm{STZ}$, compared with controls (Figure 3). There was a significant negative correlation between PDH activity and STZ dose. In contrast, medium chain acylcoenzyme A dehydrogenase (MCAD) activity, an enzyme involved in fatty acid $\beta$-oxidation, was significantly increased in $30 \mathrm{mg} / \mathrm{kg} \mathrm{STZ}$ diabetic rats, compared with controls. These changes in PDH and MCAD activity were independent of a change in the Krebs cycle enzyme citrate synthase, used as a marker of overall mitochondrial content.

\section{Cardiac metabolic proteins}

As the changes in metabolic enzymes displayed dosedependent relationships between STZ dose and activities, we, therefore, investigated which doses of STZ induced changes in metabolic protein expression. Proteins involved in cardiac glucose metabolism were investigated in our model of type 2 diabetes, to determine if this pathway was downregulated in diabetic hearts (Figure 4). Protein levels of the PDH inhibitor pyruvate dehydrogenase kinase 4 (PDK4), were increased by all doses of STZ compared with controls. In contrast, the insulinresponsive glucose transporter, GLUT4, protein levels decreased with all doses of STZ, compared with control hearts. Both PDK4 and GLUT4 displayed dosedependent relationships with STZ concentrations $\left(\mathrm{r}^{2}=\right.$ 0.53 and $r^{2}=0.22$, respectively, $\left.\mathrm{p}<0.05\right)$. GLUT1 protein levels showed no significant differences between groups. Markers of cardiac fatty acid metabolism were also assessed, to determine if this pathway was upregulated in our diabetic hearts (Figure 5). Uncoupling protein 3 (UCP3), a fatty acid regulated protein, was increased by
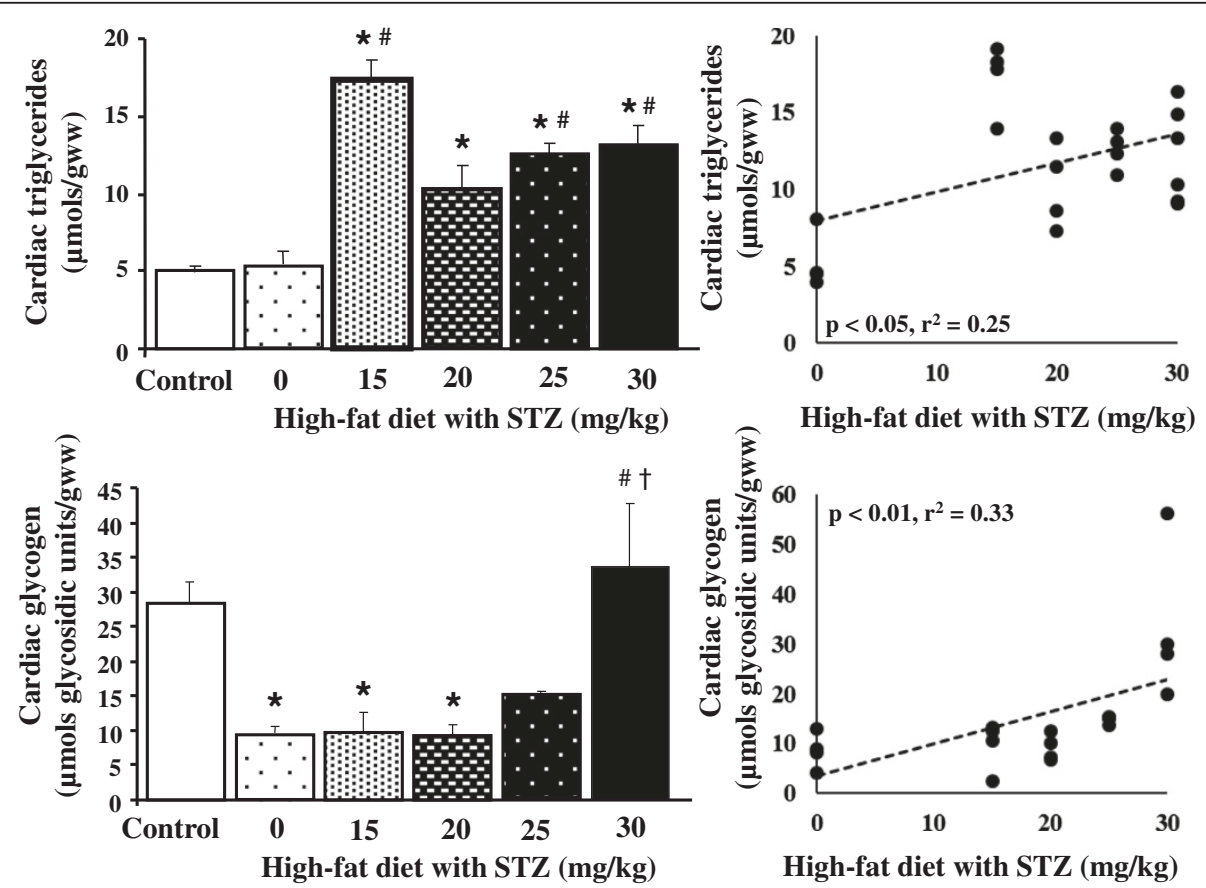

Figure 2 Cardiac triglyceride and glycogen concentrations in control and diabetic rats following high-fat feeding in combination with low dose STZ. * $p<0.05$ vs. control, \# $p<0.05$ vs. high-fat only, $+p<0.05$ vs. 15 and 20 mg/kg STZ, $n=9$ for control group, $n=4$ for diabetic groups. 

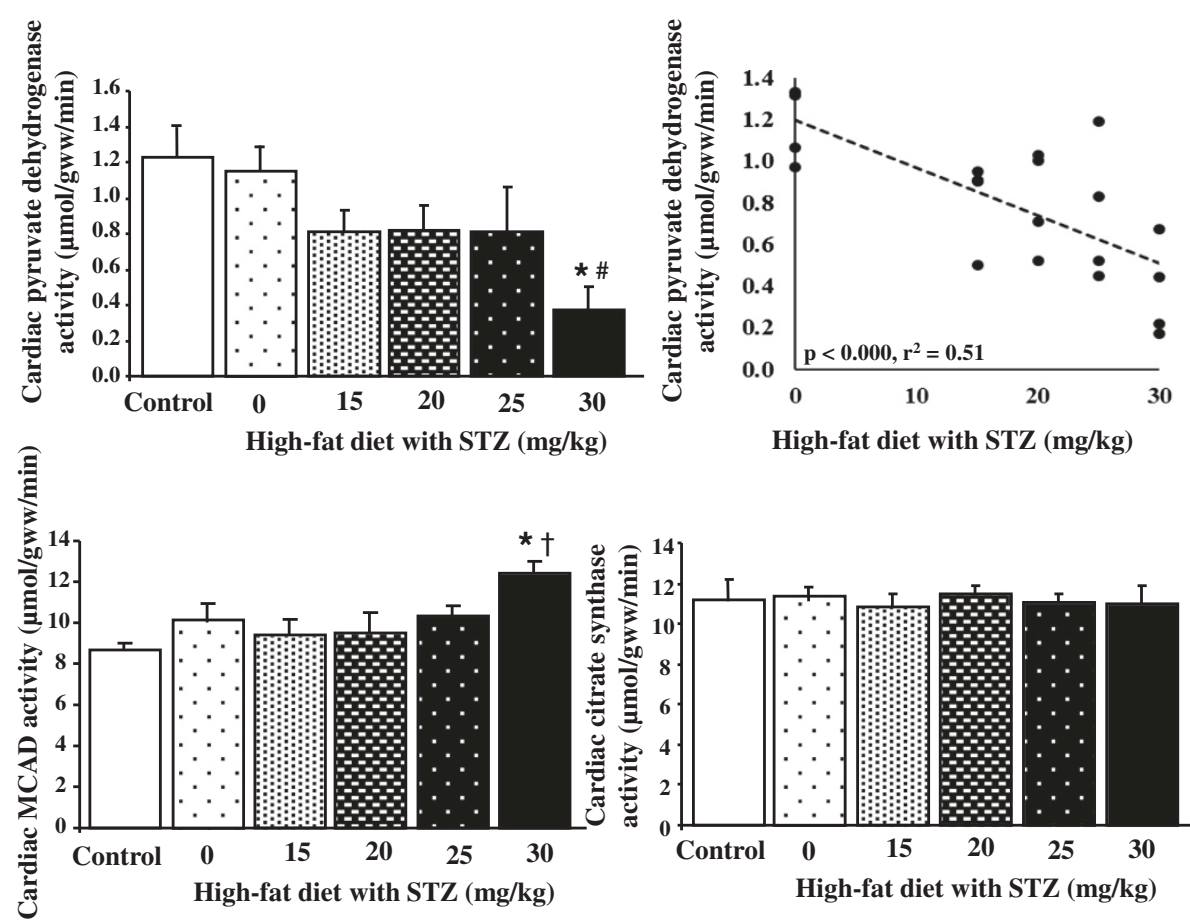

Figure 3 Cardiac pyruvate dehydrogenase, medium chain acyl-coenzyme A dehydrogenase (MCAD) and citrate synthase activities in control and diabetic rats following high-fat feeding in combination with low dose STZ. ${ }^{*} p<0.05$ vs. control, \# $p<0.05$ vs. high-fat only, t $p<0.05$ vs. 15 and $20 \mathrm{mg} / \mathrm{kg} \mathrm{STZ,} n=4-5$ per group.

all doses of STZ compared with control hearts, increasing in a dose-dependent manner with STZ concentration $\left(\mathrm{r}^{2}=0.34, \mathrm{p}<0.05\right)$. FAT/CD36, a fatty acid transporter, was not significantly different between groups when assessed by one way ANOVA. MCT1, responsible for ketone body and monocarboxylic acid uptake, was measured, to determine if changes in this transporter mirrored changes in plasma ketone bodies. There were no significant differences between groups in cardiac MCT1 protein levels, although there was a general trend for lower levels in diabetic hearts compared with control hearts.

\section{Cardiac glycolytic rates from $15 \mathrm{mg} / \mathrm{kg} \mathrm{STZ} \mathrm{high-fat} \mathrm{fed}$ diabetic rats}

All doses of STZ investigated showed a downregulation of glucose metabolism proteins, therefore, we questioned whether this was sufficient to affect flux through the glycolytic pathway in the perfused, contracting heart. Given that a number of metabolic changes in these hearts displayed a dose-dependent relationship, we rationalised that if we saw a change in glycolysis with the lowest dose $(15 \mathrm{mg} / \mathrm{kg} \mathrm{STZ})$, then this would likely indicate that overall the model was sufficient to inhibit cardiac glucose metabolic flux (Figure 6).

Hearts from $15 \mathrm{mg} / \mathrm{kg}$ STZ high-fat fed diabetic rats did not show any defects in contractile function. Heart rates $(284 \pm 13$ and $264 \pm 5 \mathrm{bpm}$ in control and diabetic hearts, respectively), developed pressures (165 \pm 10 and $182 \pm 10 \mathrm{mmHg}$ in control and diabetic hearts, respectively), and rate pressure products $(47 \pm 4$ and $48 \pm 3 \times$ $10^{3} \mathrm{mmHg} / \mathrm{min}$ in control and diabetic hearts, respectively) were not significantly different between control and $15 \mathrm{mg} / \mathrm{kg} \mathrm{STZ} \mathrm{diabetic} \mathrm{hearts.} \mathrm{In} \mathrm{contrast,} \mathrm{glycolytic}$ rates in the presence of insulin were significantly decreased by $17 \%$ in $15 \mathrm{mg} / \mathrm{kg}$ type 2 diabetic rat hearts compared with control hearts. Thus, even at the lowest dose of STZ, glycolytic rates were suppressed in the hearts of these type 2 diabetic rats.

\section{Discussion}

This study has demonstrated that high-fat feeding in combination with a low dose of STZ is sufficient to induce the cardiac metabolic phenotype present in type 2 diabetes. In general, this model displayed hyperglycaemia, normoinsulinaemia and hepatic lipid deposition. Diabetic hearts had decreased proteins involved in glucose metabolism with a concomitant increase in proteins involved in fat metabolism. Many metabolic parameters displayed a dose-dependent relationship with STZ, with the highest dose of STZ inducing a metabolic profile that more closely resembled type 1 diabetes. Therefore, this model of type 2 diabetes would appear to mirror the human condition, but care must be taken when 


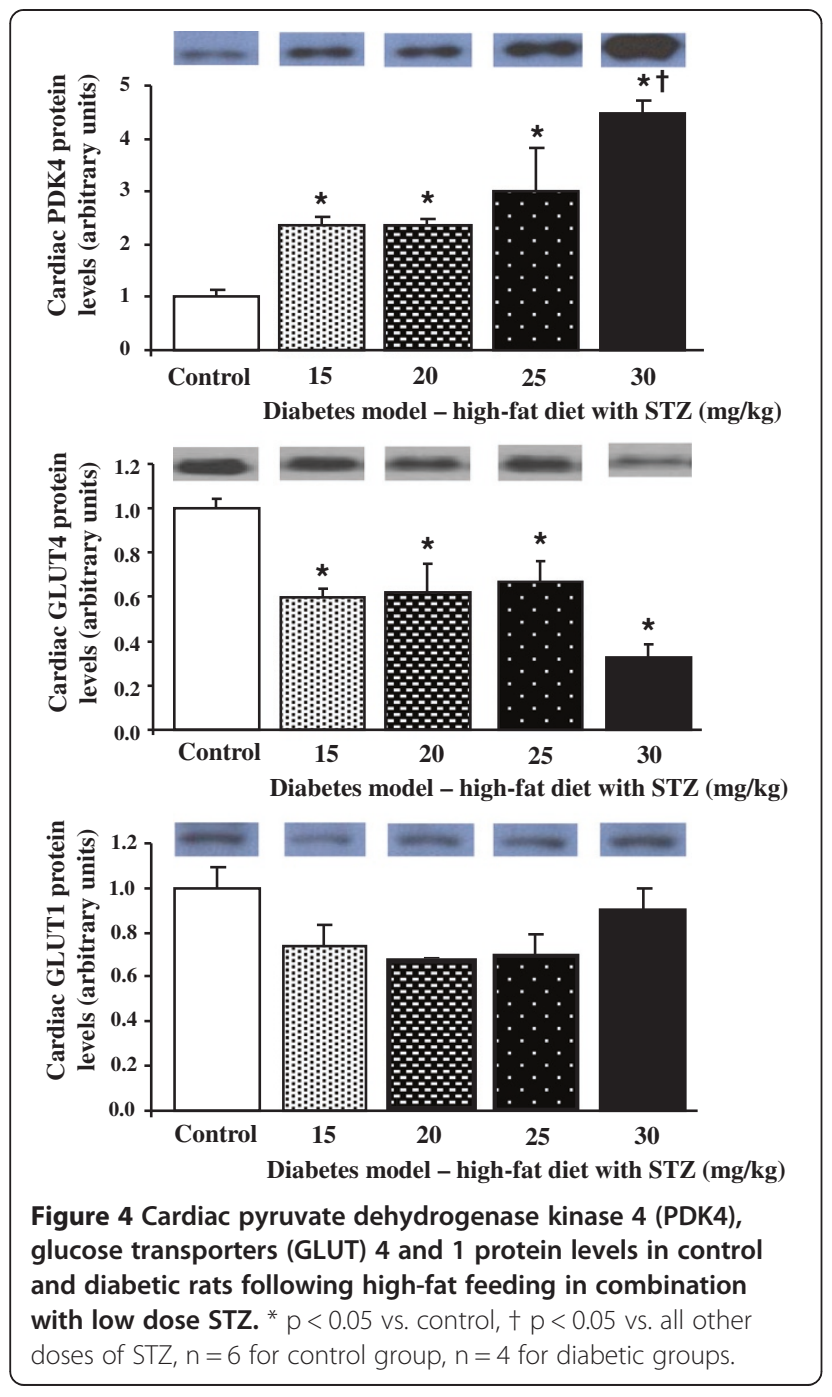

determining the dose of STZ to use and the subsequent degree of diabetes induced.

The highest dose of STZ tested $(30 \mathrm{mg} / \mathrm{kg}$ ) induced systemic changes that more closely resembled the type 1 diabetic phenotype. Only this high dose of STZ induced weight loss, and produced a plasma metabolite profile that included hyperketonaemia, hyperlipidaemia, and hypoinsulinaemia. This is in agreement with other studies that have used high doses of STZ in isolation or in combination with high-fat feeding [19,36-39], with these high doses also causing abnormalities in liver morphology and function [25]. In contrast, the lower doses of STZ investigated in the present study avoided these extreme phenotypes, instead presenting with hyperglycaemia in the absence of ketosis, normoinsulinaemia and with maintenance of body weight. Increased adiposity relative to body weight was observed with doses of 20 ,

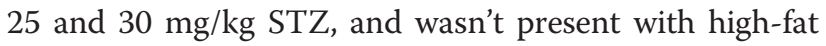
diet only, demonstrating a combined effect of the dietary
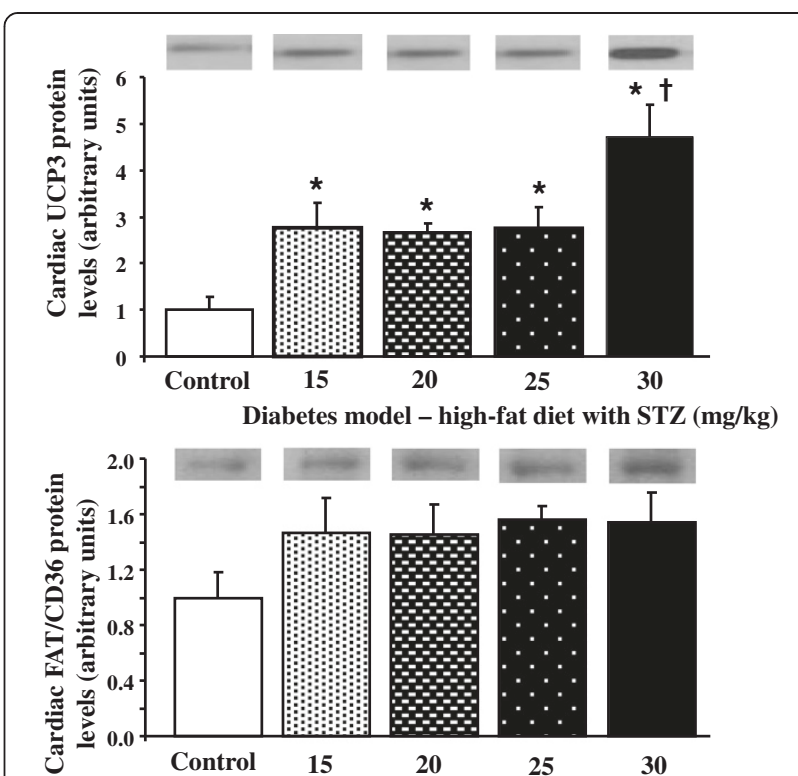

Diabetes model - high-fat diet with STZ $(\mathrm{mg} / \mathrm{kg})$

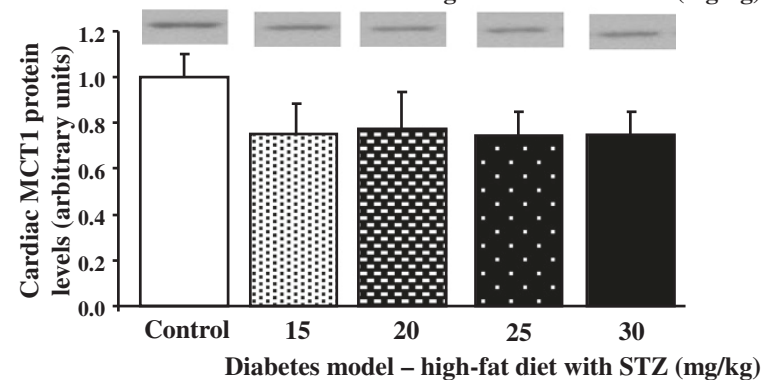

Figure 5 Cardiac uncoupling protein 3 (UCP3), fatty acid translocase (FAT/CD36) and monocarboxylate transporter 1 (MCT1) protein levels in control and diabetic rats following high-fat feeding in combination with low dose STZ. * $p<0.05$ vs. control, $+p<0.05$ vs. all other doses of STZ, $n=6$ for control group, $n=4$ for diabetic groups.

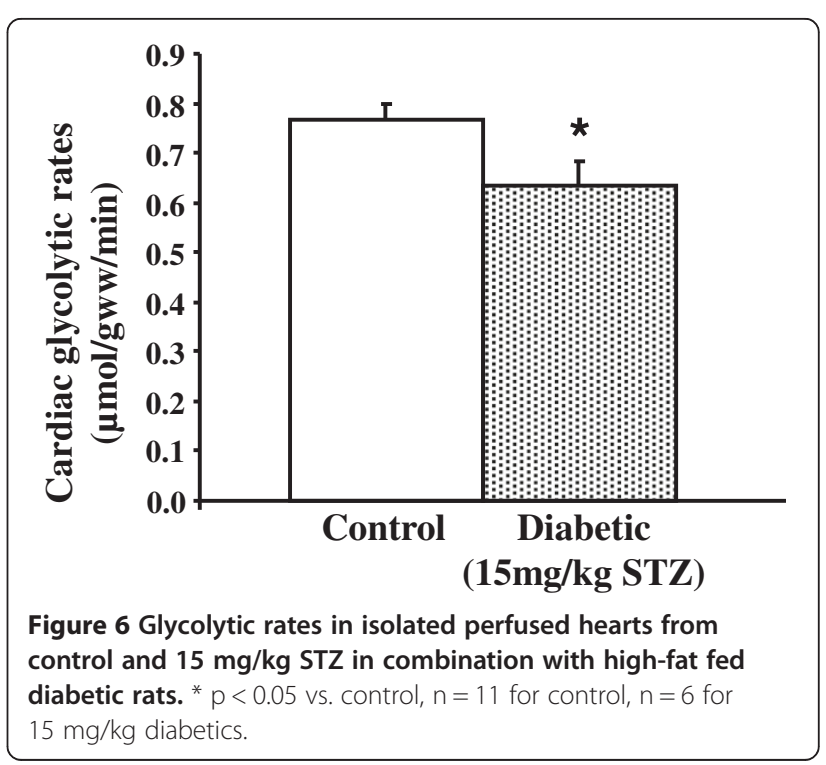


manipulation and STZ administration. The increased adiposity and elevated cholesterol induced by $25 \mathrm{mg} / \mathrm{kg}$ STZ are features present in other models of type 2 diabetes [40-42], suggesting that, from a systemic point of view, the middle range dose of STZ tested was the most desirable for future work.

In patients with type 2 diabetes, non-invasive imaging studies have demonstrated a metabolic shift in cardiac substrate metabolism [3-6], with glucose metabolism suppressed and fatty acids metabolism elevated, characteristic of the Randle cycle [43]. This metabolic shift has been demonstrated in a number of animal models of diabetic cardiomyopathy [44,45], and has been implicated in the increased incidence of, and decreased recovery following, myocardial infarction [2]. In our diabetic hearts, we found markers of fatty acid oxidation, such as UCP3, were upregulated. UCP3, MCAD and PDK4 are peroxisome proliferator-activated receptor $\alpha$ (PPAR $\alpha)$ targets, a transcription factor that is activated by fatty acid ligands to upregulate fat metabolism, and is increased in diabetes [46]. The activation of PPAR $\alpha$ in diabetes is due to both the increased intake of dietary fatty acids, in addition to increased adipose lipolysis associated with adipose insulin resistance [47]. In contrast to fatty acid metabolism, proteins involved in cardiac glucose metabolism, such as GLUT4, were downregulated in our diabetic hearts. Certainly, the large increase in

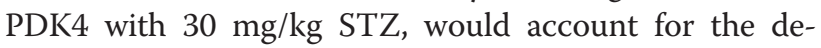
crease in PDH activity in these hearts via inhibitory phosphorylation of this complex. Thus, the changes in protein and enzyme activity in our diabetic hearts would fully support the shift away from glucose metabolism towards fat metabolism, reported in other models and in patient studies [48]. Future studies to measure the effects on fatty acid and oxidative metabolism in this model will confirm the link between the changes in mitochondrial proteins and flux through these pathways.

Perfused heart studies allow the simultaneous measurement of metabolic flux and contractile function in the isolated organ. Even at the lowest dose of STZ, glycolytic rates were decreased, confirming that our changes in proteins were sufficient to impact on overall flux through the pathway, in agreement with studies on $d b / d b$ and $o b / o b$ mice $[44,45,49,50]$. The decrease in glycolysis was independent of impaired cardiac systolic function or loss of mitochondria, suggesting that the glycolytic changes were not secondary to adverse cardiac remodelling and mitophagy. In a clever study by Marsh et al., the interaction between diet and diabetes on cardiovascular function was investigated, using a similar model to our current study [51]. They demonstrated that a combination of high-fat feeding and low dose STZ increased diastolic wall stress and arterial stiffness, as occurs in patients with type 2 diabetes, but that modifying only diet or using only STZ did not produce this effect, despite increased blood glucose and abnormal insulin tolerance tests, respectively [51]. Thus, inducing type 2 diabetes using high-fat feeding and low dose STZ, not only mimics the cardiac metabolic phenotype but also replicates the diastolic dysfunction and vascular complications associated with the human disease.

Overall, these data support the use of the high-fat diet/low dose STZ approach in the development of a type 2 diabetic model for future cardiac studies. The advantages of this model are that the disease is induced over a relatively short time and without high costs. In addition, the dose of STZ can be manipulated to match the degree of diabetes required for the study. In a study by Watts et al., this model of high-fat diet and low dose STZ was used and directly compared to the ZDF rat, with both models demonstrating the same hepatic and adipose effects, but the errors associated with the ZDF animals were much greater than with the high-fat/STZ model, suggesting that the reproducibility may be improved by using this new model [22]. Similarly, in a study by Islam and Choi, the high-fat diet in combination with low dose STZ model was identified as a better model of type 2 diabetes than an alternative chemicallyinduced model that utilised an injection of nicotinamide prior to administration of STZ [37]. We found it was essential to fast the rats prior to STZ injection, as preliminary experiments demonstrated a much lower success rate for inducing diabetes if injections were carried out in the fed state (data not shown). This is likely related to the mode of action of STZ, a glucosamine-nitrosourea antibiotic that competes with blood glucose for the pancreatic $\beta$-cell GLUT2 receptor [20].

Hepatic and cardiac triglyceride concentrations were elevated by all doses of STZ tested but not by high-fat diet alone, indicating that this was due to the combination of STZ and high-fat. Hepatic and cardiac glycogen concentrations showed dose-dependent relationships with STZ concentrations, but in opposite directions in the two organs; decreasing in liver but increasing in heart. Interestingly, hepatic glycogen was not affected by high-fat diet alone, in contrast, cardiac glycogen was significantly decreased just by the presence of high-fat diet, demonstrating different regulation of glycogen deposition in these two organs.

From our data, doses of $30 \mathrm{mg} / \mathrm{kg} \mathrm{STZ}$ (and potentially above) would be less desirable than lower doses for modelling type 2 diabetes, due to the extreme systemic phenotype induced. However, at no time did we see an increase in fed insulin concentrations, which has been observed in a number of other models. It has been suggested that this is due to STZ causing a small degree of $\beta$-cell damage, which is sufficient to limit the upregulation of insulin secretion in response to the 
systemic insulin resistance [19]. Srinivasan et al. demonstrated that $35 \mathrm{mg} / \mathrm{kg} \mathrm{STZ} \mathrm{had} \mathrm{no} \mathrm{effect} \mathrm{on} \mathrm{insulin} \mathrm{con-}$ centrations in chow fed rats, whereas high-fat feeding in isolation increased insulin, with the combination of high-fat and STZ bringing insulin concentrations back to control levels [19]. Using a glucose tolerance test, they demonstrated systemic insulin resistance with high-fat diet alone [19]. Thus, it could be that our model using $30 \mathrm{mg} / \mathrm{kg} \mathrm{STZ} \mathrm{mimics} \mathrm{a} \mathrm{later} \mathrm{stage} \mathrm{in} \mathrm{type} 2$ diabetesinsulin resistance disease progression, when $\beta$-cell function starts to become compromised and no longer matches the increased demand for insulin.

In conclusion, a combination of high-fat feeding with a low dose of STZ provides a model of type 2 diabetes that mimics the metabolic phenotype present in patients. This model also has the added advantages of being relatively inexpensive, easy to induce and can be modified for different severities of diabetes, according to requirement of the study. For future studies we would use a dose of $25 \mathrm{mg} / \mathrm{kg}$ STZ in combination with high-fat feeding, as this induced adiposity, hypercholesterolemia, mild hyperglycaemia without compromising insulin secretion, and exhibited cardiac metabolic changes that mirrored the well characterised shift from glucose to fatty acid metabolism in type 2 diabetes.

\section{Additional files}

Additional file 1: Table S1. Composition of chow and high-fat diet.

Additional file 2: Figure S1. Body weight gain in control and diabetic rats. Rats were fed a chow or high-fat diet for 21 days, with STZ injected at varying doses at day $14 . \mathrm{n}=4-11$ per group.

\section{Abbreviations}

STZ: Streptozotocin; FAT/CD36: Fatty acid translocase; GLUT: Glucose transporter; PDH: Pyruvate dehydrogenase; MCAD: Medium chain acylcoenzyme A dehydrogenase; PDK: Pyruvate dehydrogenase kinase; UCP: Uncoupling protein.

\section{Competing interests}

The authors declare that they have no competing interests.

\section{Authors' contributions}

LM conducted the isolated heart perfusion experiments, enzyme assays and tissue analysis. EG and JB conducted the enzyme assays and western blotting experiments. MC, DT, CC and KC conducted the animal experiments, assisted with data analysis and helped to draft the manuscript. LH performed experiments, carried out the statistical analysis and drafted the manuscript. All authors read and approved the final manuscript.

\section{Acknowledgements}

We thank Emma Carter and Lydia Le Page for technical assistance, and Rhys Evans for constructive discussion of the data. This work was supported by grants from Diabetes UK (grant number 11/0004175) and the British Heart Foundation.

\section{Author details}

'Department of Physiology, Anatomy and Genetics, University of Oxford, Parks Road, OX1 3PT, Oxford, UK. ' University of Nottingham Medical School, Queens Medical Centre, Nottingham, UK.
Received: 31 July 2013 Accepted: 19 September 2013

Published: 24 September 2013

\section{References}

1. Morrish NJ, Wang SL, Stevens LK, Fuller JH, Keen H: Mortality and causes of death in the WHO Multinational Study of Vascular Disease in Diabetes. Diabetologia 2001, 44(Suppl 2):S14-S21.

2. Boudina S, Abel ED: Diabetic cardiomyopathy revisited. Circulation 2007, 115(25):3213-3223.

3. McGill JB, Peterson LR, Herrero P, Saeed IM, Recklein C, Coggan AR, Demoss AJ, Schechtman KB, Dence CS, Gropler RJ: Potentiation of abnormalities in myocardial metabolism with the development of diabetes in women with obesity and insulin resistance. J Nucl Cardio/ 2011, 18(3):421-429. quiz 432-423.

4. Riizewijk $L$, van der Meer RW, Lamb HJ, De Jong HW, Lubberink M, Romijn JA, Bax JJ, De Roos A, Twisk JW, Heine RJ, et al: Altered myocardia substrate metabolism and decreased diastolic function in nonischemic human diabetic cardiomyopathy: studies with cardiac positron emission tomography and magnetic resonance imaging. J Am Coll Cardiol 2009, 54(16):1524-1532

5. Labbe SM, Grenier-Larouche T, Noll C, Phoenix S, Guerin B, Turcotte EE, Carpentier AC: Increased myocardial uptake of dietary fatty acids linked to cardiac dysfunction in glucose-intolerant humans. Diabetes 2012, 61(11):2701-2710.

6. Dutka DP, Pitt M, Pagano D, Mongillo M, Gathercole D, Bonser RS, Camici PG: Myocardial glucose transport and utilization in patients with type 2 diabetes mellitus, left ventricular dysfunction, and coronary artery disease. J Am Coll Cardiol 2006, 48(11):2225-2231.

7. Bugger $\mathrm{H}$, Abel ED: Rodent models of diabetic cardiomyopathy. Dis Model Mech 2009, 2(9-10):454-466.

8. Zhang Y, Proenca R, Maffei M, Barone M, Leopold L, Friedman JM: Positional cloning of the mouse obese gene and its human homologue. Nature 1994, 372(6505):425-432.

9. Chen H, Charlat O, Tartaglia LA, Woolf EA, Weng X, Ellis SJ, Lakey ND, Culpepper J, Moore K, Breitbart RE, et al: Evidence that the diabetes gene encodes the leptin receptor: identification of a mutation in the leptin receptor gene in db/db mice. Cell 1996, 84(3):491-495.

10. Lee GH, Proenca R, Montez JM, Carroll KM, Darvishzadeh JG, Lee Jl, Friedman JM: Abnormal splicing of the leptin receptor in diabetic mice. Nature 1996, 379(6566):632-635

11. Phillips MS, Liu Q, Hammond HA, Dugan V, Hey PJ, Caskey CJ, Hess JF: Leptin receptor missense mutation in the fatty Zucker rat. Nat Genet 1996, 13(1):18-19.

12. Goto Y, Kakizaki M, Masaki N: Production of spontaneous diabetic rats by repetition of selective breeding. Tohoku J Exp Med 1976, 119(1):85-90.

13. Desrois M, Sidell RJ, Gauguier D, King LM, Radda GK, Clarke K: Initial steps of insulin signaling and glucose transport are defective in the type 2 diabetic rat heart. Cardiovasc Res 2004, 61(2):288-296.

14. Srinivasan $\mathrm{K}$, Ramarao P: Animal models in type 2 diabetes research: an overview. Indian J Med Res 2007, 125(3):451-472.

15. Wang P, Chatham JC: Onset of diabetes in Zucker diabetic fatty (ZDF) rats leads to improved recovery of function after ischemia in the isolated perfused heart. Am J Physiol Endocrinol Metab 2004, 286(5):E725-E736.

16. Sidell RJ, Cole MA, Draper NJ, Desrois M, Buckingham RE, Clarke K Thiazolidinedione treatment normalizes insulin resistance and ischemic injury in the Zucker fatty rat heart. Diabetes 2002, 51(4):1110-1117.

17. Cole MA, Murray AJ, Cochlin LE, Heather LC, McAleese S, Knight NS, Sutton E, Jamil AA, Parassol N, Clarke K: A high fat diet increases mitochondrial fatty acid oxidation and uncoupling to decrease efficiency in rat heart. Basic Res Cardiol 2011, 106(3):447-457.

18. Reed MJ, Meszaros K, Entes LJ, Claypool MD, Pinkett JG, Gadbois TM Reaven GM: A new rat model of type 2 diabetes: the fat-fed, streptozotocin-treated rat. Metabolism 2000, 49(11):1390-1394.

19. Srinivasan K, Viswanad B, Asrat L, Kaul CL, Ramarao P: Combination of high-fat diet-fed and low-dose streptozotocin-treated rat: a model for type 2 diabetes and pharmacological screening. Pharmacol Res 2005, 52(4):313-320

20. Schnedl WJ, Ferber S, Johnson JH, Newgard CB: STZ transport and cytotoxicity. Specific enhancement in GLUT2-expressing cells. Diabetes 1994, 43(11):1326-1333. 
21. Gunnarsson R, Berne C, Hellerstrom C: Cytotoxic effects of streptozotocin and $\mathrm{N}$-nitrosomethylurea on the pancreatic $\mathrm{B}$ cells with special regard to the role of nicotinamide-adenine dinucleotide. Biochem J 1974, 140(3):487-494.

22. Watts LM, Manchem VP, Leedom TA, Rivard AL, McKay RA, Bao D, Neroladakis T, Monia BP, Bodenmiller DM, Cao JX, et al: Reduction of hepatic and adipose tissue glucocorticoid receptor expression with antisense oligonucleotides improves hyperglycemia and hyperlipidemia in diabetic rodents without causing systemic glucocorticoid antagonism. Diabetes 2005, 54(6):1846-1853.

23. Cao S, Li B, Yi X, Chang B, Zhu B, Lian Z, Zhang Z, Zhao G, Liu H, Zhang H: Effects of exercise on AMPK signaling and downstream components to PI3K in rat with type 2 diabetes. PLoS One 2012, 7(12):e51709.

24. Salman ZK, Refaat $R$, Selima E, Sarha AE, Ismail MA: The combined effect of metformin and L-cysteine on inflammation, oxidative stress and insulin resistance in streptozotocin-induced type 2 diabetes in rats. Eur J Pharmacol 2013, 714(1-3):448-455.

25. Sahin K, Onderci M, Tuzcu M, Ustundag B, Cikim G, Ozercan IH, Sriramoju V, Juturu V, Komorowski JR: Effect of chromium on carbohydrate and lipid metabolism in a rat model of type 2 diabetes mellitus: the fat-fed, streptozotocin-treated rat. Metabolism 2007, 56(9):1233-1240.

26. Epp RA, Susser SE, Morissettee MP, Kehler DS, Jassal DS, Duhamel TA: Exercise training prevents the development of cardiac dysfunction in the low-dose streptozotocin diabetic rats fed a high-fat diet. Can J Physiol Pharmacol 2013, 91(1):80-89.

27. Zhang F, Ye C, Li G, Ding W, Zhou W, Zhu H, Chen G, Luo T, Guang M, Liu $Y$, et al: The rat model of type 2 diabetic mellitus and its glycometabolism characters. Exp Anim 2003, 52(5):401-407.

28. Seymour AM, Chatham JC: The effects of hypertrophy and diabetes on cardiac pyruvate dehydrogenase activity. J Mol Cell Cardiol 1997, 29(10):2771-2778.

29. Lehman TC, Hale DE, Bhala A, Thorpe C: An acyl-coenzyme A dehydrogenase assay utilizing the ferricenium ion. Anal Biochem 1990 186(2):280-284.

30. Srere P: Citrate synthase. Methods Enzymol 1969, 13:3-5.

31. Heather LC, Cole MA, Lygate CA, Evans RD, Stuckey DJ, Murray AJ, Neubauer S, Clarke K: Fatty acid transporter levels and palmitate oxidation rate correlate with ejection fraction in the infarcted rat heart. Cardiovasc Res 2006, 72(3):430-437.

32. Bonen A, Luiken JJ, Arumugam Y, Glatz JF, Tandon NN: Acute regulation of fatty acid uptake involves the cellular redistribution of fatty acid translocase. J Biol Chem 2000, 275(19):14501-14508.

33. Heather LC, Cole MA, Atherton HJ, Coumans WA, Evans RD, Tyler DJ, Glatz JF, Luiken JJ, Clarke K: Adenosine monophosphate-activated protein kinase activation, substrate transporter translocation, and metabolism in the contracting hyperthyroid rat heart. Endocrinology 2010, 151(1):422-431.

34. Holman GD, Kozka IJ, Clark AE, Flower CJ, Saltis J, Habberfield AD, Simpson IA, Cushman SW: Cell surface labeling of glucose transporter isoform GLUT4 by bis-mannose photolabel. Correlation with stimulation of glucose transport in rat adipose cells by insulin and phorbol ester. J Biol Chem 1990, 265(30):18172-18179.

35. Sugden MC, Kraus A, Harris RA, Holness MJ: Fibre-type specific modification of the activity and regulation of skeletal muscle pyruvate dehydrogenase kinase (PDK) by prolonged starvation and refeeding is associated with targeted regulation of PDK isoenzyme 4 expression. Biochem J 2000, 346(Pt 3):651-657.

36. Nikooie R, Rajabi H, Gharakhanlu R, Atabi F, Omidfar K, Aveseh M, Larijani B: Exercise-induced changes of MCT1 in cardiac and skeletal muscles of diabetic rats induced by high-fat diet and STZ. J Physiol Biochem 2013. doi:10.1007/s13105-013-1263-6.

37. Islam MS, Choi H: Nongenetic model of type 2 diabetes: a comparative study. Pharmacology 2007, 79(4):243-249.

38. King LM, Sidell RJ, Wilding JR, Radda GK, Clarke K: Free fatty acids, but not ketone bodies, protect diabetic rat hearts during low-flow ischemia. Am J Physiol Heart Circ Physiol 2001, 280(3):H1173-H1181.

39. Schroeder MA, Cochlin LE, Heather LC, Clarke K, Radda GK, Tyler DJ: In vivo assessment of pyruvate dehydrogenase flux in the heart using hyperpolarized carbon-13 magnetic resonance. Proc Natl Acad Sci USA 2008, 105(33):12051-12056
40. Aasum E, Hafstad AD, Severson DL, Larsen TS: Age-dependent changes in metabolism, contractile function, and ischemic sensitivity in hearts from $\mathrm{db} / \mathrm{db}$ mice. Diabetes 2003, 52(2):434-441

41. Buchanan J, Mazumder PK, Hu P, Chakrabarti G, Roberts MW, Yun UJ, Cooksey RC, Litwin SE, Abel ED: Reduced cardiac efficiency and altered substrate metabolism precedes the onset of hyperglycemia and contractile dysfunction in two mouse models of insulin resistance and obesity. Endocrinology 2005, 146(12):5341-5349.

42. Turley SD, Hansen CT: Rates of sterol synthesis in the liver and extrahepatic tissues of the SHR/N-corpulent rat, an animal with hyperlipidemia and insulin-independent diabetes. J Lipid Res 1986, 27(5):486-496.

43. Randle PJ, Garland PB, Hales CN, Newsholme EA: The glucose fatty-acid cycle. Its role in insulin sensitivity and the metabolic disturbances of diabetes mellitus. Lancet 1963, 1:785-789.

44. Belke DD, Larsen TS, Gibbs EM, Severson DL: Altered metabolism causes cardiac dysfunction in perfused hearts from diabetic $(\mathrm{db} / \mathrm{db})$ mice. Am J Physiol Endocrinol Metab 2000, 279(5):E1104-E1113.

45. Mazumder PK, O'Neill BT, Roberts MW, Buchanan J, Yun UJ, Cooksey RC, Boudina S, Abel ED: Impaired cardiac efficiency and increased fatty acid oxidation in insulin-resistant ob/ob mouse hearts. Diabetes 2004, 53(9):2366-2374.

46. Finck BN, Kelly DP: Peroxisome proliferator-activated receptor alpha (PPARalpha) signaling in the gene regulatory control of energy metabolism in the normal and diseased heart. J Mol Cell Cardiol 2002, 34(10):1249-1257.

47. Eriksson JW, Smith U, Waagstein F, Wysocki M, Jansson PA: Glucose turnover and adipose tissue lipolysis are insulin-resistant in healthy relatives of type 2 diabetes patients: is cellular insulin resistance a secondary phenomenon? Diabetes 1999, 48(8):1572-1578.

48. Sarkozy M, Zvara A, Gyemant N, Fekete V, Kocsis GF, Pipis J, Szucs G, Csonka C, Puskas LG, Ferdinandy $P$, et al: Metabolic syndrome influences cardiac gene expression pattern at the transcript level in male ZDF rats. Cardiovasc Diabetol 2013, 12:16

49. Panagia M, Schneider JE, Brown B, Cole MA, Clarke K: Abnormal function and glucose metabolism in the type-2 diabetic $\mathrm{db} / \mathrm{db}$ mouse heart Can J Physiol Pharmacol 2007, 85(3-4):289-294.

50. Hafstad AD, Solevag GH, Severson DL, Larsen TS, Aasum E: Perfused hearts from Type 2 diabetic ( $\mathrm{db} / \mathrm{db}$ ) mice show metabolic responsiveness to insulin. Am J Physiol Heart Circ Physiol 2006, 290(5):H1763-H1769.

51. Marsh SA, Dell'italia $\amalg$, Chatham JC: Interaction of diet and diabetes on cardiovascular function in rats. Am J Physiol Heart Circ Physiol 2009 296(2):H282-H292

doi:10.1186/1475-2840-12-136

Cite this article as: Mansor et al:: Cardiac metabolism in a new rat model of type 2 diabetes using high-fat diet with low dose streptozotocin. Cardiovascular Diabetology 2013 12:136

\section{Submit your next manuscript to BioMed Central and take full advantage of:}

- Convenient online submission

- Thorough peer review

- No space constraints or color figure charges

- Immediate publication on acceptance

- Inclusion in PubMed, CAS, Scopus and Google Scholar

- Research which is freely available for redistribution 